\title{
Article \\ Oral Health-Related Quality of Life in Anticoagulated Patients with Warfarin Treatment: A Cross-Sectional Study
}

\author{
Johana Alejandra Moreno-Drada ${ }^{1, *(\mathbb{D}}$, Alex Junio Silva da Cruz ${ }^{1} \mathbb{D}^{\mathbb{D}}$, Matheus Luis Soares de Faria $^{1}$, \\ Luís Otávio Miranda Cota ${ }^{1}$, Maria Auxiliadora Parreiras Martins ${ }^{2}$, Isabela Almeida Pordeus ${ }^{1}$ and \\ Mauro Henrique Nogueira Guimarães de Abreu ${ }^{1}$ (D)
}

1 School of Dentistry, Universidade Federal de Minas Gerais, Belo Horizonte CEP 31270-901, Brazil; junio.alex@hotmail.com (A.J.S.d.C.); matheuslsfaria@gmail.com (M.L.S.d.F.); luisotaviocota@gmail.com (L.O.M.C.); isabela.pordeus@gmail.com (I.A.P.); maurohenriqueabreu@gmail.com (M.H.N.G.d.A.)

2 Department of Pharmaceutical Products, Universidade Federal of Minas Gerais, Belo Horizonte CEP 31270-901, Brazil; auxiliadorapmartins@hotmail.com

* Correspondence: joalmodra@hotmail.com

Citation: Moreno-Drada, J.A.; Silva da Cruz, A.J.; Soares de Faria, M.L.; Miranda Cota, L.O.; Parreiras Martins, M.A.; Almeida Pordeus, I.; Nogueira Guimarães de Abreu, M.H. Oral Health-Related Quality of Life in Anticoagulated Patients with Warfarin Treatment: A

Cross-Sectional Study. Int. J. Environ. Res. Public Health 2021, 18, 3714. https://doi.org/10.3390/ ijerph18073714

Academic Editors: Katherine Chiu Man Leung and Chun Hung Chu

Received: 20 February 2021

Accepted: 30 March 2021

Published: 2 April 2021

Publisher's Note: MDPI stays neutra with regard to jurisdictional claims in published maps and institutional affiliations.

Copyright: (C) 2021 by the authors Licensee MDPI, Basel, Switzerland. This article is an open access article distributed under the terms and conditions of the Creative Commons Attribution (CC BY) license (https:// creativecommons.org/licenses/by/ $4.0 /)$

\begin{abstract}
To evaluate factors associated with oral health-related quality of life (OHRQoL) in patients under oral anticoagulant therapy with warfarin, a cross-sectional study was conducted. Validated questionnaires assessed self-reported periodontal disease, demographic variables, and OHRQoL using the short version of the Oral Health Impact Profile (OHIP-14) instrument. After calibration (Kappa > 0.60), an examiner evaluated patients' experience with dental caries and the need for dental prostheses. Statistical analysis involved proportions and measures of central tendency. Negative binomial regression models were used to estimate the rate ratios (RR) and the corresponding 95\% confidence interval (CI). The sample consisted of 158 individuals, with a mean age of 58.8 years $(\mathrm{SD}=12.1)$, of which $62.7 \%$ of the participants were women. The OHIP-14 mean was 10.62 (SD = 10.92). A higher OHIP-14 total score (worse OHRQoL) was associated with ethnic group, age, periodontal disease self-report, dental caries, and oral health self-report. Demographic and clinical factors can negatively influence the perception of anticoagulated patients on OHRQoL.
\end{abstract}

Keywords: anticoagulants; oral health; quality of life; oral health-related quality of life

\section{Introduction}

Oral anticoagulant therapy (OAT) has increased in recent years [1,2], especially due to the increase in life expectancy [3]. OAT is recommended for outpatients with atrial fibrillation, prosthetic heart valves, venous thromboembolism, acute coronary syndrome or myocardial infarction, and pulmonary hypertension for prevention and treatment, reducing the risk of stroke-related morbidity and mortality [2,4-8]. Coumarin derivatives, such as warfarin, are the most commonly used drugs, especially in low and middle-income countries [6,9-11]. The efficacy and safety of warfarin depend on achieving the desired therapeutic range, monitored by the international normalized ratio (INR) [2,12]. Both insufficient and excessive anticoagulation effects can be harmful, increasing thromboembolic and hemorrhagic risks, respectively [2].

Although prior studies are scarce in the literature, oral health plays an essential role in individuals on oral anticoagulation. Meurman et al. [13] identified that part of the OAT patients had never brushed their teeth. The fear of gingival bleeding may well induce individuals to brush their teeth less frequently, increasing the number of plaque-covered teeth and causing deep gingival pockets $[13,14]$. Moreover, the population undergoing OAT tends to be older $[3,15]$. Other conditions increase their prevalence and severity in aged patients, such as periodontal disease, decreased salivary flow, and reduced host defenses, leading to different oral diseases. These conditions and insufficient knowledge 
of oral health may contribute to inadequate oral hygiene [14]. As a result, extractions in patients undergoing OAT are frequent $[7,9,14]$. The loss of teeth may also negatively influence essential oral functions [16].

The interest in Patient-Reported Outcome Measures (PROMs) in clinical research has been growing lately. The use of PROMs to assess the oral health related quality of life (OHRQoL) allows us to understand the impact of oral conditions on the subjects' daily lives, a perspective that would probably not be achieved by clinical indicators [17]. Previous studies identified that the OHRQoL could be affected by sociodemographic factors, such as age, sex, ethnicity, and socioeconomic level [18-20]. Similarly, periodontal disease, teeth (decayed, missing, or filled), mucosal lesions, and denture problems were prevalent and showed a negative association with OHRQoL $[19,21,22]$. By contrast, a systematic review stated no consensus in the literature on the association between edentulism, caries, and periodontal conditions and OHRQoL [23]. Despite the increasing publications about this topic, there is limited knowledge about the behaviors, feelings, or repercussions of oral conditions in individuals undergoing OAT.

The risk of bleeding, dietary intake restrictions, and possible interactions of oral anticoagulants, such as warfarin, with other medications can interfere with daily activities in people undergoing OAT $[8,24,25]$. These events can affect the general quality of life of the population that uses oral anticoagulants. In addition to the uncertainties associated with OAT, there is an increased risk of oral bleeding due to oral diseases that can cause dissatisfaction and have a significant negative impact upon OHRQoL [14,25]. However, the scientific community has paid little attention to the interaction between complex long-term treatments, such as OAT and oral health care, and the impact oral health has on one's quality of life $[14,25]$. Considering that most patients who receive oral anticoagulation suffer from chronic diseases that may be severe or life-threatening and undergo continuous drug treatment throughout their lives, the role of oral health and its impact on the quality of life in this population is unclear. Thus, this study aims to analyze the factors associated with OHRQoL in patients on OAT with warfarin.

\section{Materials and Methods}

The Ethics Committee for Human Research from Universidade Federal de Minas Gerais (UFMG) (logged under protocol number CAAE 17726219.0.0000.5149) approved the conduction of this study. Patients signed an informed consent form; participation was voluntary, and patients could refuse to answer any questions.

\subsection{Participants and Data Collection}

Outpatients from the Brazilian National Health System (SUS in Portuguese) undergoing oral anticoagulant treatment during 2019 at the Anticoagulation Clinic of the Hospital das Clínicas of UFMG were evaluated. The anticoagulation clinic is multidisciplinary, with established protocols for patient education and dose adjustments [11]. A consecutive sample of patients was selected. The patients under medical treatment at the Anticoagulation Clinic of the Hospital das Clínicas of UFMG and those who were eligible and gave authorization were recruited consecutively. The sample calculation was performed with a $95 \%$ confidence level $(\mathrm{CI})$ and an $80 \%$ power and the comparison of means on the information about the impact of untreated dental caries on the quality of life, considering the study of De Oliveira et al. [26], resulting in a minimum of 120 patients for the sample size. Considering the possibility of missing data for some variables, we added $30 \%$ to this sample size, resulting in a minimum of 156 patients.

This study included patients of $\geq 18$ years of age on oral anticoagulation with warfarin. Exclusion criteria were: patients with insufficient information in their medical history, individuals that could not communicate their answers to the questions asked, or patients with spontaneous bleeding before the dental examination.

Data were collected from October 2019 to February 2020. Each patient was asked to answer a structured questionnaire with a combination of sociodemographic questions: 
the Brazilian version of the Oral Health Impact Profile (OHIP-14) [26], which has been designed to measure the perception of the social impact of oral disorders $[27,28]$, together with the periodontal disease self-report instrument [29].

\subsection{Instruments}

The self-reported periodontal disease instrument evaluated sociodemographic information, risk factors for periodontal disease, self-reported oral health measures, and periodontal status. The preferred clinical examination is periodontal probing, and although it remains the gold standard for the diagnosis of periodontitis [29], it was not considered in this group of patients. The explanation is given because many patients on warfarin have heart diseases [30] or prosthetic heart valves with a risk for infective endocarditis [31], treated with the recommendation of antibiotic prophylaxis before dental procedures involving the manipulation of the gingival tissue, the periapical region of the teeth, or perforation of the oral mucosa [32]. The clinical evaluation would imply a risk of gingival bleeding that is difficult to control or a risk of endocarditis, in addition to the need to implement prophylactic antibiotic therapy. Moreover, the self-reported periodontal disease instrument has shown good accuracy in identifying sick individuals, especially those with severe periodontitis. The sensitivity and specificity showed a moderate to good value in identifying periodontal disease in different predictive models [29].

The OHIP-14 is a specific indicator of OHRQoL, which demonstrated good reliability and validity [28]. The OHIP-14 items involved the evaluation of seven conceptual subscales: functional limitation, physical pain, psychological distress, physical disability, psychological disability, social disability, and handicap [26]. The dependent variable analyzed in this study was the OHIP-14, with 14 questions and an answer possibility from 0 to 4 . The total score range was 0 to 56 , where the highest OHIP-14 score indicated a worse quality of life. The mean and median values of OHIP-14 were calculated for each covariate.

\subsection{Face-to-Face Interviews and Clinical Examination}

Trained researchers conducted face-to-face interviews. Prior to the fieldwork, an examiner underwent a training and calibration exercise to diagnose dental caries. Calibration was carried out using images from different clinical situations on two separate occasions. A pilot study was conducted before the fieldwork, where ten adult patients were evaluated at the School of Dentistry at Universidade Federal de Minas Gerais. The calibration level was observed through a Cohen's Kappa coefficient above 0.60, which is considered adequate. A clinical examination was performed using DMFT index (decayed, missing, and filled teeth index) to assess the patients' caries experience. Its value was expressed by the sum of decayed, missing, and filled teeth to obtain an individual index. The use or not of prostheses and the type of prostheses were clinically established [33].

\subsection{Statistical Analysis}

This analysis involved descriptive analysis, together with the calculation of proportions and central tendency and variability measures. Negative binomial regression models were used to estimate the unadjusted and adjusted rate ratios (RR) and corresponding $95 \%$ CI. First, unadjusted negative binomial regression models were carried out to estimate unadjusted RR (95\% CI) and $p$-values for each of the 35 covariates included one by one. In this first step, any covariate with a $p$-value of less than 0.25 was a candidate to be tested in the final adjusted negative binomial regression model. As the focus of interest was on the independent effects of each covariate, all potential variables were included in the unadjusted model, which had age, sex, self-reported skin color, place of residence, smoking, tooth brushing frequency, gum disease, tooth migration, oral health, periodontal surgery, decayed (DMFT index) tooth indicated for extraction, and need for a prosthesis. Only covariates with a $p$-value lower than 0.05 were maintained in the final model when all variables would be presented together. The ratio between residual deviance and degree of freedom, as well as results from the chi-squared test of the residual deviance, was indicated 
to evaluate the goodness of fit of the final model [34,35]. Missing data were not computed in the statistical analysis. Variation Inflation Factor (VIF) was calculated for multicollinearity diagnosis. Statistical analyses were carried out in SPSS statistics software Version 24 (IBM, Chicago, IL, USA).

\section{Results}

The surveyed sample included 158 patients. The mean age (SD) was 58.8 (12.0) years, with a predominance of the female sex $(62.7 \%)$, and $26.6 \%$ of the individuals reported that their skin color was white. We found ten patients who reported being smokers. The range number of cigarettes per day was 7 to 20, with a mean of 7.2 and a standard deviation of 5.96 .

Regarding the indications for OAT, the results showed that the majority of patients had some fibrillation (19.7\% non-valve atrial fibrillation/flutter and $23.7 \%$ valve atrial fibrillation/flutter) or some prosthetic heart valves ( $4.6 \%$ with biological valve prosthesis (mitral), 27.0\% with mechanical valve prosthesis (aortic) and 34.2\% with mechanical valve prosthesis (mitral)). The sum of these diagnoses was higher than $100 \%$, considering that the same patient could have more than one OAT indication.

The mean of the years of school of the included patients was $6.63( \pm 3.87)$. The mean OHIP-14 of the sample was $10.6( \pm 10.9)$. The descriptive characteristics of the patients included in this study are presented in Table 1.

Table 1. Characteristics of the patients under anticoagulation therapy with warfarin, Belo Horizonte, Brazil, 2019-2020.

\begin{tabular}{|c|c|c|}
\hline Quantitative Variables & Mean (SD) & $\begin{array}{l}\text { Minimum- } \\
\text { Maximum }\end{array}$ \\
\hline OHIP14- Oral Health Impact Profile $(N=158)$ & $10.62(10.92)$ & $0-53$ \\
\hline Functional limitation $(N=158)$ & $1.35(2.03)$ & $0-8$ \\
\hline Physical pain $(N=158)$ & $2.48(2.35)$ & $0-8$ \\
\hline Psychological discomfort $(N=158)$ & $2.35(2.70)$ & $0-8$ \\
\hline Physical disability $(N=158)$ & $1.53(2.19)$ & $0-8$ \\
\hline Psychological disability $(N=158)$ & $1.52(2.07)$ & $0-8$ \\
\hline Social disability $(N=158)$ & $0.54(1.30)$ & $0-8$ \\
\hline Handicap $(N=158)$ & $0.85(1.59)$ & $0-8$ \\
\hline Age $(N=158)$ & $58.80(12.05)$ & 27-91 \\
\hline Years of school $(N=158)$ & $6.63(3.87)$ & $0-20$ \\
\hline INR-International normalized ratio $(N=157)$ & $2.61(0.82)$ & $1.06-5.40$ \\
\hline Number of teeth self-report $(N=154)$ & $14.94(11.02)$ & $0-36$ \\
\hline $\begin{array}{l}\text { DMFT index- Decayed, missing, and filled teeth } \\
\text { index }(N=158)\end{array}$ & $22.92(7.57)$ & $1-32$ \\
\hline Decayed (DMFT index) $(N=158)$ & $1.10(1.85)$ & $0-18$ \\
\hline Missing (DMFT index) $(N=158)$ & $16.23(10.96)$ & $0-32$ \\
\hline Tooth indicated for extraction $(N=158)$ & $0.27(1.45)$ & $0-17$ \\
\hline Filled teeth (DMFT index) $(N=158)$ & $5.43(5.75)$ & $0-24$ \\
\hline Categorical Variables & Frequency & $\%$ \\
\hline \multicolumn{3}{|l|}{$\operatorname{Sex}(N=158)$} \\
\hline Male & 59 & 37.3 \\
\hline Female & 99 & 62.7 \\
\hline \multicolumn{3}{|l|}{ Skin color $(N=158)$} \\
\hline White & 42 & 26.6 \\
\hline Others & 116 & 73.4 \\
\hline \multicolumn{3}{|l|}{ Place of residence $(N=158)$} \\
\hline Belo Horizonte & 83 & 52.5 \\
\hline Small cities near Belo Horizonte & 75 & 47.5 \\
\hline
\end{tabular}


Table 1. Cont.

\begin{tabular}{|c|c|c|}
\hline Categorical Variables & Frequency & $\%$ \\
\hline \multicolumn{3}{|l|}{ Education level $(N=158)$} \\
\hline Up to 8 years of formal education & 96 & 60.8 \\
\hline More than 8 years of formal education & 62 & 39.2 \\
\hline \multicolumn{3}{|l|}{ Household Income $(N=158)$} \\
\hline$<1$ Minimum wage & 11 & 7.0 \\
\hline$>1$ Minimum wage & 147 & 93.0 \\
\hline Alcohol consumption $(N=158)$ & 22 & 13.9 \\
\hline Smoking $(N=158)$ & 13 & 8.2 \\
\hline Diabetes $(N=157)$ & 21 & 13.4 \\
\hline Dental flossing $(N=158)$ & 93 & 58.9 \\
\hline \multicolumn{3}{|l|}{ Dental flossing frequency $(N=93)$} \\
\hline Occasionally & 44 & 47.3 \\
\hline Daily & 49 & 52.7 \\
\hline \multicolumn{3}{|l|}{ Tooth brushing frequency $(N=158)$} \\
\hline Once a day & 10 & 6.3 \\
\hline Twice a day or more & 148 & 93.7 \\
\hline \multicolumn{3}{|l|}{ Last dental checkup $(N=157)$} \\
\hline Up to 6 months & 61 & 38.9 \\
\hline 1 year or more & 96 & 61.1 \\
\hline Gum disease $(N=125)$ & 37 & 29.6 \\
\hline Tooth migration $(N=123)$ & 46 & 37.4 \\
\hline Tooth mobility $(N=125)$ & 38 & 30.4 \\
\hline Tooth loss $(N=124)$ & 13 & 10.5 \\
\hline \multicolumn{3}{|l|}{ Oral health $(N=157)$} \\
\hline Excellent/Very Good/Good & 114 & 72.6 \\
\hline Poor/Fair & 43 & 27.4 \\
\hline Scaling and root planing $(N=124)$ & 87 & 70.2 \\
\hline Periodontal surgery $(N=125)$ & 10 & 8.0 \\
\hline Bone loss $(N=125)$ & 24 & 19.2 \\
\hline Use of maxillary prostheses $(N=158)$ & 84 & 53.2 \\
\hline Use of mandibular prostheses $(N=158)$ & 51 & 32.3 \\
\hline \multicolumn{3}{|l|}{ Need for general prostheses $(N=158)$} \\
\hline Needs maxillary and mandibular prostheses & 71 & 44.9 \\
\hline $\begin{array}{l}\text { Needs only maxillary prosthesis or only } \\
\text { mandibular prosthesis }\end{array}$ & 43 & 27.2 \\
\hline None required & 44 & 27.8 \\
\hline Need for maxillary prostheses $(N=158)$ & 80 & 50.6 \\
\hline Need for mandibular prostheses $(N=158)$ & 105 & 66.5 \\
\hline
\end{tabular}

Minimum wage in Brazil is BRL 1100.00 (Real), which is approximately equivalent to USD 200.00 (American Dollar)

The final multivariate-adjusted model consisted of ten variables. Individuals from other races were more likely to have poor OHRQoL than white individuals $(\mathrm{RR}=1.047$; 95\% CI 1.024-1.070). Older individuals were less likely to have poor OHRQoL (RR = 0.998; 95\% CI 0.997-0.999). Patients who reported poor or fair oral health were more likely to have poor OHRQoL $(\mathrm{RR}=1.055 ; 95 \%$ CI 1.028-1.083) than those who reported excellent, very good, or good oral health. Patients who reported gingival disease (RR $=1.031 ; 95 \% \mathrm{CI}$ 1.013-1.048), dental migration $(\mathrm{RR}=1.034 ; 95 \% \mathrm{CI} 1.011-1.057)$, scaling and root planing $(\mathrm{RR}=1.027 ; 95 \% \mathrm{CI} 1.006-1.048)$, and periodontal surgery $(\mathrm{RR}=1.032 ; 95 \% \mathrm{CI} 1.010-1.055)$ had poor OHRQoL. Likewise, the individuals that presented more decayed $(\mathrm{RR}=1.006$; 
95\% CI 1.003-1.008), missing $(\mathrm{RR}=1.002 ; 95 \%$ CI 1.001-1.004), and filled teeth $(\mathrm{RR}=1.004 ;$ 95\% CI 1.002-1.006) also had poor OHRQoL (Table 2). Parameters of the goodness of fit were adequate. The chi-squared test of the residual deviance results, with a $p$-value equal to 0.997 , and the ratio between residual deviance and degree of freedom resulted in 1.078, indicating that the model fit well. VIF values were all lower than 10 , showing no problem with collinearity.

Table 2. Factors associated with oral health related quality of life among patients under anticoagulation therapy with warfarin. Belo Horizonte, Brazil, 2019-2020.

\begin{tabular}{|c|c|c|c|c|c|}
\hline Variable & $\begin{array}{l}\text { OHIP-14 Scores } \\
\text { (Mean; Median) }\end{array}$ & $\begin{array}{c}\text { Unadjusted Rate } \\
\text { Ratio }(95 \% \text { CI) }\end{array}$ & $p$ Value & $\begin{array}{l}\text { Adjusted Rate } \\
\text { Ratio (95\% CI) }\end{array}$ & $p$ Value \\
\hline $\begin{array}{l}\text { Sex }(N=158) \\
\text { Male }(N=59) \\
\text { Female }(N=99)\end{array}$ & $\begin{array}{l}6.2 ; 4.0 \\
10.3 ; 9.0\end{array}$ & $\begin{array}{c}1 \\
1.079(1.036-1.126)\end{array}$ & $<0.001$ & & \\
\hline $\begin{array}{l}\text { Skin color }(N=158) \\
\text { White }(N=42) \\
\text { Others }(N=116)\end{array}$ & $\begin{array}{c}5.9 ; 4.0 \\
12.3 ; 8.0\end{array}$ & $\begin{array}{c}1 \\
1.081(1.025-1.142)\end{array}$ & 0.004 & $\begin{array}{c}1 \\
1.047 \\
(1.024-1.070)\end{array}$ & $<0.001$ \\
\hline Age $(N=158)$ & & $0.998(0.997-0.999)$ & $<0.001$ & $\begin{array}{c}0.998 \\
(0.997-0.999)\end{array}$ & $<0.001$ \\
\hline INR- International normalized ratio $(N=157)$ & & $0.999(0.978-1.019)$ & 0.895 & & \\
\hline $\begin{array}{l}\text { Place of residence }(N=158) \\
\text { Belo Horizonte }(N=83) \\
\text { Small cities near of Belo Horizonte }(N=75)\end{array}$ & $\begin{array}{c}9.4 ; 7.0 \\
11.9 ; 8.0\end{array}$ & $\begin{array}{c}1 \\
1.021(0.993-1.049)\end{array}$ & 0.140 & & \\
\hline $\begin{array}{l}\text { Education level }(N=158) \\
\text { Up to } 8 \text { years of formal education }(N=96) \\
\text { More than } 8 \text { years of formal education }(N=62)\end{array}$ & $\begin{array}{l}10.5 ; 7.0 \\
10.9 ; 9.0\end{array}$ & $\begin{array}{c}1 \\
1.003(0.976-1.031)\end{array}$ & 0.808 & & \\
\hline $\begin{array}{l}\text { Household Income }(N=158) \\
<1 \text { Minimum wage }(N=11) \\
>1 \text { Minimum wage }(N=147)\end{array}$ & $\begin{array}{l}10.9 ; 6.0 \\
10.6 ; 7.0\end{array}$ & $\begin{array}{c}1 \\
0.998(0.930-1.069)\end{array}$ & 0.945 & & \\
\hline $\begin{array}{l}\text { Alcohol consumption }(N=158) \\
\text { No }(N=136) \\
\text { Yes }(N=22)\end{array}$ & $\begin{array}{l}10.5 ; 7.0 \\
11.2 ; 8.0\end{array}$ & $\begin{array}{c}1 \\
1.005(0.961-1.051)\end{array}$ & 0.826 & & \\
\hline $\begin{array}{l}\text { Smoking }(N=158) \\
\text { No }(N=145) \\
\text { Yes }(N=13)\end{array}$ & $\begin{array}{c}11.2 ; 8.0 \\
4.1 ; 4.0\end{array}$ & $\begin{array}{c}1 \\
0.878(0.801-0.962)\end{array}$ & 0.005 & & \\
\hline $\begin{array}{l}\text { Diabetes }(N=157) \\
\text { No }(N=136) \\
\text { Yes }(N=21)\end{array}$ & $\begin{array}{l}10.6 ; 7.0 \\
11.3 ; 9.0\end{array}$ & $\begin{array}{c}1 \\
1.005(0.973-1.039)\end{array}$ & 0.756 & & \\
\hline $\begin{array}{l}\text { Dental flossing }(N=158) \\
\text { No }(N=65) \\
\text { Yes }(N=93)\end{array}$ & $\begin{array}{l}8.0 ; 6.0 \\
12.4 ; 9.0\end{array}$ & $\begin{array}{c}1 \\
1.040(1.009-1.073)\end{array}$ & 0.010 & & \\
\hline $\begin{array}{l}\text { Dental flossing frequency }(N=158) \\
\text { Occasionally or not use }(N=109) \\
\text { Daily }(N=49)\end{array}$ & $\begin{array}{l}10.1 ; 6.0 \\
11.8 ; 9.0\end{array}$ & $\begin{array}{c}1 \\
1.013(0.986-1.040)\end{array}$ & 0.345 & & \\
\hline $\begin{array}{l}\text { Tooth brushing frequency }(N=158) \\
\text { Once a day }(N=10) \\
\text { Twice a day or more }(N=148)\end{array}$ & $\begin{array}{l}10.3 ; 7.0 \\
10.6 ; 7.0\end{array}$ & $\begin{array}{c}1 \\
1.003(0.944-1.065)\end{array}$ & 0.926 & & \\
\hline $\begin{array}{l}\text { Last dental checkup }(N=157) \\
\text { Up to } 6 \text { months }(N=61) \\
1 \text { year or more }(N=96)\end{array}$ & $\begin{array}{l}10.3 ; 7.0 \\
10.9 ; 7.0\end{array}$ & $\begin{array}{c}1 \\
0.995(0.968-1.023)\end{array}$ & 0.739 & & \\
\hline $\begin{array}{l}\text { Gingival disease }(N=125) \\
\text { No }(N=88) \\
\text { Yes }(N=37)\end{array}$ & $\begin{array}{c}8.6 ; 6.0 \\
17.0 ; 13.0\end{array}$ & $\begin{array}{c}1 \\
1.054(1.026-1.083)\end{array}$ & $<0.001$ & $\begin{array}{c}1 \\
1.031 \\
(1.013-1.048)\end{array}$ & 0.001 \\
\hline $\begin{array}{l}\text { Dental migration }(N=123) \\
\text { No }(N=77) \\
\text { Yes }(N=46)\end{array}$ & $\begin{array}{c}7.8 ; 6.0 \\
16.9 ; 16.5\end{array}$ & $\begin{array}{c}1 \\
1.066(1.034-1.098)\end{array}$ & $<0.001$ & $\begin{array}{c}1 \\
1.034 \\
(1.011-1.057)\end{array}$ & 0.003 \\
\hline $\begin{array}{l}\text { Tooth mobility }(N=125) \\
\text { No }(N=87) \\
\text { Yes }(N=38)\end{array}$ & $\begin{array}{c}9.3 ; 6.0 \\
15.7 ; 12.5\end{array}$ & $\begin{array}{c}1 \\
1.013(1.013-1.069)\end{array}$ & 0.003 & & \\
\hline
\end{tabular}


Table 2. Cont.

\begin{tabular}{|c|c|c|c|c|c|}
\hline Variable & $\begin{array}{l}\text { OHIP-14 Scores } \\
\text { (Mean; Median) }\end{array}$ & $\begin{array}{l}\text { Unadjusted Rate } \\
\text { Ratio (95\% CI) }\end{array}$ & $p$ Value & $\begin{array}{l}\text { Adjusted Rate } \\
\text { Ratio (95\% CI) }\end{array}$ & $p$ Value \\
\hline $\begin{array}{l}\text { Tooth loss }(N=124) \\
\text { No }(N=111) \\
\text { Yes }(N=13)\end{array}$ & $\begin{array}{l}10.9 ; 7.0 \\
12.8 ; 9.0\end{array}$ & $1.013(0.985-1.042)$ & 0.364 & & \\
\hline $\begin{array}{l}\text { Oral health }(N=157) \\
\text { Excellent/Very Good/Good }(N=114) \\
\text { Poor/Fair }(N=43)\end{array}$ & $\begin{array}{c}7.0 ; 5.0 \\
20.4 ; 19.0\end{array}$ & $\begin{array}{c}1 \\
1.090(1.061-1.120)\end{array}$ & $<0.001$ & $\begin{array}{c}1 \\
1.055 \\
(1.028-1.083)\end{array}$ & $<0.001$ \\
\hline $\begin{array}{l}\text { Scaling and root planing }(N=124) \\
\text { No }(N=37) \\
\text { Yes }(N=87)\end{array}$ & $\begin{array}{c}9.1 ; 6.0 \\
12.2 ; 9.0\end{array}$ & $\begin{array}{c}1 \\
1.026(0.989-1.064)\end{array}$ & 0.174 & $\begin{array}{c}1 \\
1.027 \\
(1.006-1.048)\end{array}$ & 0.011 \\
\hline $\begin{array}{l}\text { Periodontal surgery }(N=125) \\
\text { No }(N=115) \\
\text { Yes }(N=10)\end{array}$ & $\begin{array}{c}10.6 ; 7.0 \\
18.0 ; 21.0\end{array}$ & $\begin{array}{c}1 \\
1.036(1.012-1.061)\end{array}$ & 0.003 & $\begin{array}{c}1 \\
1.032 \\
(1.010-1.055)\end{array}$ & 0.004 \\
\hline $\begin{array}{l}\text { Bone loss }(N=125) \\
\text { Yes }(N=24) \\
\text { No }(N=101)\end{array}$ & $\begin{array}{l}14.2 ; 10.0 \\
10.5 ; 7.0\end{array}$ & $1.023(0.998-1.049)$ & 0.074 & & \\
\hline Number of teeth self-reported $(N=154)$ & & $1.001(1.000-1.002)$ & 0.188 & & \\
\hline $\begin{array}{l}\text { Use of maxillary prostheses }(N=158) \\
\text { No }(N=74) \\
\text { Yes }(N=84)\end{array}$ & $\begin{array}{l}10.8 ; 8.0 \\
10.5 ; 6.0\end{array}$ & $0.998(0.971-1.026)$ & 0.859 & & \\
\hline $\begin{array}{l}\text { Use of mandibular prostheses }(N=158) \\
\text { No }(N=107) \\
\text { Yes }(N=51)\end{array}$ & $\begin{array}{l}11.6 ; 8.0 \\
8.5 ; 6.0\end{array}$ & $0.972(0.939-1.006)$ & 0.107 & & \\
\hline $\begin{array}{l}\text { Need for general prostheses }(N=158) \\
\text { Needs maxillary and mandibular prostheses } \\
(N=71) \\
\text { Needs only maxillary prosthesis or only } \\
\text { mandibular prosthesis }(N=43) \\
\text { None required }(N=44)\end{array}$ & $\begin{array}{c}12.7 ; 8.0 \\
10.0 ; 8.0 \\
7.9 ; 4.5\end{array}$ & $\begin{array}{c}1 \\
0.981(0.951-1.013) \\
0.957(0.919-0.997)\end{array}$ & $\begin{array}{l}0.238 \\
0.035\end{array}$ & & \\
\hline $\begin{array}{l}\text { Need for maxillary prostheses }(N=158) \\
\text { No }(N=78) \\
\text { Yes }(N=80)\end{array}$ & $\begin{array}{c}9.1 ; 6.0 \\
12.1 ; 8.0\end{array}$ & $1.024(0.996-1.054)$ & 0.091 & & \\
\hline $\begin{array}{l}\text { Need for mandibular prostheses }(N=158) \\
\text { No }(N=53) \\
\text { Yes }(N=105)\end{array}$ & $\begin{array}{c}7.8 ; 6.0 \\
12.1 ; 8.0\end{array}$ & $1.042(1.004-1.081)$ & 0.029 & & \\
\hline DMFT index-Decayed, missing, and filled teeth & $\operatorname{lex}(N=158)$ & $1.000(0.998-1.001)$ & 0.788 & & \\
\hline Decayed (DMFT index) $(N=158)$ & & $1.004(1.003-1.005)$ & $<0.001$ & $\begin{array}{c}1.006 \\
(1.003-1.008)\end{array}$ & $<0.001$ \\
\hline Missing (DMFT index) $(N=158)$ & & $0.999(0.998-1.000)$ & 0.190 & $\begin{array}{c}1.002 \\
(1.001-1.004)\end{array}$ & 0.007 \\
\hline Tooth indicated for extraction $(N=158)$ & & $1.004(1.003-1.005)$ & $<0.001$ & & \\
\hline Filled Teeth $(\mathrm{DMFT})(N=158)$ & & $1.001(0.999-1.003)$ & 0.190 & $\begin{array}{c}1.004 \\
(1.002-1.006)\end{array}$ & $<0.001$ \\
\hline
\end{tabular}

Minimum wage in Brazil is BRL 1100.00 (Real), which is approximately equivalent to USD 200.00 (American Dollar).

\section{Discussion}

We found that the OHRQoL is associated with some sociodemographic factors, periodontal self-reported factors, and other clinical factors. White and older individuals were less likely to have poor OHRQoL. Patients who reported gingival disease, dental migration, scaling and root planing, periodontal surgery, poor or fair oral health, and more decayed, missing, and filled teeth had poor OHRQoL.

Almost half of the OHIP-14 value refers to the dimensions of psychological discomfort and pain. We must bear in mind that most oral problems do not represent an immediate risk of death; however, they are responsible for reducing the quality of life of individuals, prolonging pain states, causing functional, aesthetic, and nutritional problems, and due to everything above, leading to psychological issues [36]. High levels of stress, anxiety, and depression have been reported in patients with dental pain in the literature, reducing the quality of life [37]. 
Some authors have discussed the relationship between ethnic groups and OHRQoL. White individuals tend to show better oral status than other ethnic groups. This situation occurs because they tend to exhibit the highest social grade [38-40]. Ethnicity was the only social factor associated with OHRQoL in our study, which is different from that observed in other studies $[18,19]$. This is possibly because the present study was performed in a public hospital where most of the population presented low income and education levels.

Oral health problems have become a significant issue in old age. These problems include tooth loss, edentulism, clinical attachment loss, coronal and root caries, oral mucosa lesions, the use of non-functional dental prostheses (partial or total), chewing problems, among other conditions [21,41]. As seen in other studies, we expected a greater impact on OHRQoL in older people [18,42]; however, our findings showed the opposite. Some feasible explanations prove that dental esthetics is related to a person's self-esteem and social interaction. Older adults seem more likely to be satisfied with their dental appearance than younger individuals [43]. Since dental esthetics may not be of primary concern among elders, this fact does not necessarily impact or impact the OHRQoL less in this age group. Moreover, dental perceptions are subjective and are associated with cultural characteristics and personality profiles [44]. This result was expected due to a variance in OHIP-14 scores, depending on the societal values where the construct was applied.

Severe periodontitis has been related to the OHRQoL [45-48]. The literature showed that the difference in OHIP-14 scores for patients with a probing depth $>6 \mathrm{~mm}$ was statistically more significant than for patients with a probing depth $<6 \mathrm{~mm}$. Likewise, periodontal surgery was a statistically significant predictor for the OHIP-14 score [45]. Similarly, this study demonstrated the importance of gingival disease, tooth migration, scaling and root planing, and periodontal surgery related to OHRQoL. Moreover, the self-reported periodontal disease instrument allows one to understand the perception that individuals have regarding their oral and periodontal health. This perspective could be relevant to understand the impact of oral conditions on one's quality of life. It is important to reinforce that a high percentage of patients in our study would need antibiotic prophylaxis before clinical examination considering their health condition [30-32]. In this clinical situation, the utility of self-report measures for periodontal disease is once more justified.

Untreated dental caries, poor self-perception of oral health, and tooth loss have already been associated with poor OHRQoL $[27,49,50]$. Even a meta-analysis reported that tooth loss is associated with unfavorable OHRQoL scores, regardless of the study location and the OHRQoL instrument [49]. These are consistent with our findings. Individuals with untreated dental caries may experience pain, mouth infection, and tooth loss, affecting adults' productivity at work, social interaction, and other daily activities. Furthermore, untreated caries represent a significant social, biological, and financial burden on individuals [51], negatively impacting OHRQoL and needing to be controlled using a population approach [52].

Our study identified that patients using warfarin have factors associated with OHRQoL, similar to the general population, as shown by a systemic review. This review indicates that different studies reported poor OHRQoL in individuals with tooth loss, periodontal disease, and dental caries in the general population [53]. Even though our research did not analyze a group without OAT, we consider that this study provides information on the impact of oral health on the daily life of patients undergoing OAT. Despite the fact that taking warfarin was not a covariate in our study, future investigations that allow such a comparison are recommended. Some tested covariates were not associated with OHRQoL. Alcohol consumption, smoking, and diabetes were not associated with OHRQoL. Associations of these variables and quality of life have been reported in the literature; however, these associations are directed to alcohol abuse [54], impaired glycemic control or complications of diabetes [55], and the number of cigarettes smoked [56]. In our study, the details of these variables were not analyzed according to the amount of alcohol or cigarettes, nor were glycemic control or diabetes complications analyzed. 
Subjective perceptions linked to culture and personality [44] may have altered the association of OHRQoL with sex and dental prostheses. Some studies related that women had a poorer OHRQoL compared to men [18,42], most likely explained by the fact that women are more affected by their physical appearance [57]. On the other hand, OHRQoL has been better in people who use dental prostheses than those who do not use and/or need them [19,57-59]. However, this study found no associations between sex or dental prostheses and OHRQoL. Perhaps, similar to age, dental esthetics played an essential role in the non-association of these variables. For this sample on oral anticoagulation, dental esthetics may not have been a primary concern. Nevertheless, most of the partial dentate and edentulous rehabilitated subjects used removable prostheses in the analyzed sample. A prior study reported that removable prostheses did not constitute an essential factor in determining good or bad OHRQoL [60]. Furthermore, a systematic review noted that in longer follow-ups ( $>9$ months), removable partial dentures did not improve OHRQoL [61].

Some limitations of this study need to be acknowledged. First, this study uses a cross-sectional design, and the temporal relationship and causality between the outcome and the exposure cannot be determined. In this way, it cannot be guaranteed that the exposure preceded the outcome because there was no follow-up. In other words, it will be difficult to determine whether a particular factor is a cause or the result of another element. Longitudinal studies are needed to assess the temporality and causality of exposure [62,63]. Our sample is not selected at random, and our results have no external validity. Moreover, despite the fact that some values of RR are statistically significant, their effect on OHRQoL could be considered small. Despite the limitations, some strengths should also be highlighted. This study provides information on the impact of oral health on the daily life of patients undergoing OAT. This information can contribute to the decisions of public policymakers regarding the oral health of the population using oral anticoagulants. The impact of OHRQoL was also evaluated in a group of patients undergoing chronic medical treatment, and this evaluation is not common in the literature. Therefore, we recommend conducting future longitudinal research that improves the knowledge of oral conditions and the OHRQoL of this population. This study expands one's understanding of the impact that oral diseases and other variables have on the OHRQoL of anticoagulated patients. It is important to highlight the importance of an interdisciplinary team focused on a comprehensive approach to the patient with systemic pathologies. This information, which is a rare topic of discussion in the literature, may well be useful when organizing oral health care in this growing population.

\section{Conclusions}

Demographic and oral health condition factors can influence poor OHRQoL among anticoagulated patients with warfarin. Oral health and psychological factors are important for a better OHRQoL in this type of increasing population.

Author Contributions: Conceptualization, J.A.M.-D., A.J.S.d.C., L.O.M.C., M.A.P.M. and M.H.N.G.d.A.; data curation, J.A.M.-D., A.J.S.d.C. and M.L.S.d.F.; formal analysis, J.A.M.-D. and M.H.N.G.d.A.; investigation, J.A.M.-D., A.J.S.d.C., M.L.S.d.F., L.O.M.C., M.A.P.M. and M.H.N.G.d.A.; methodology, J.A.M.-D., A.J.S.d.C., M.L.S.d.F., L.O.M.C. and M.H.N.G.d.A.; software, I.A.P.; validation, I.A.P. and M.H.N.G.d.A.; resources, I.A.P.; writing—original draft preparation, J.A.M.-D., A.J.S.d.C., M.A.P.M. and M.H.N.G.d.A.; writing—review and editing, J.A.M.-D., A.J.S.d.C., M.A.P.M. and M.H.N.G.d.A.; visualization, I.A.P. and M.H.N.G.d.A.; supervision, I.A.P. and M.H.N.G.d.A.; project administration, I.A.P.; funding acquisition, I.A.P. All authors contributed to the study conception, design, material preparation, data collection, and analysis. All authors have read and agreed to the published version of the manuscript.

Funding: This study was supported by the Brazilian agencies: Conselho Nacional de Desenvolvimento Científico e Tecnológico (CNPq) and Coordenação de Aperfeiçoamento de Pessoal de Nível Superior (CAPES). 
Institutional Review Board Statement: This study was performed in line with the principles of the Declaration of Helsinki. Approval was granted by the Ethics Committee for Human Research of the Universidade Federal de Minas Gerais (protocol no. CAAE 17726219.0.0000.5149).

Informed Consent Statement: Informed consent was obtained from all individual participants included in the study.

Data Availability Statement: All data and materials, as well as a software application or custom code, support the published claims and comply with field standards.

Conflicts of Interest: The authors declare no conflict of interest.

\section{References}

1. Kaplovitch, E.; Dounaevskaia, V. Treatment in the Dental Practice of the Patient Receiving Anticoagulation Therapy. J. Am. Dent. Assoc. 2019, 150, 602-608. Available online: https://pubmed.ncbi.nlm.nih.gov/31109636/ (accessed on 15 January 2021). [CrossRef] [PubMed]

2. Boned-Ombuena, A.; Pérez-Panadés, J.; López-Maside, A.; Miralles-Espí, M.; Vilarroig, S.G.; Ruiz, D.A.; Zurriaga, O. Prevalencia de la anticoagulación oral y calidad de su seguimiento en el ámbito de la atención primaria: Estudio de la Red Centinela Sanitaria de la Comunitat Valenciana [Prevalence of oral anticoagulation and quality of its management in primary healthc. Atención Primaria 2017, 49, 534-548. [CrossRef]

3. Lee, J.K. Dental Management of Patients on Anti-Thrombotic Agents. J. Korean Assoc. Oral Maxillofac. Surg. 2018, 44, 143-150. Available online: https://pubmed.ncbi.nlm.nih.gov/30181980/ (accessed on 15 January 2021). [CrossRef] [PubMed]

4. Ripollés de, R.J.; Gómez, F.R.; Muñoz-Corcuera, M.; Bascones, M.A. Actualización en Los Protocolos de Extracción Dental en Pacientes Anticoagulados [Update in Dental Procedures in Patients Receiving Oral Anticoagulated Therapy]. Av. Odontoestomatol. 2012, 28, 311-320. Available online: http://scielo.isciii.es/pdf/odonto/v28n6/original5.pdf (accessed on 15 January 2021). [CrossRef]

5. Kämmerer, P.W.; Frerich, B.; Liese, J.; Schiegnitz, E.; Al-Nawas, B. Oral Surgery during Therapy with Anticoagulants-A Systematic Review. Clin. Oral Investig. 2015, 19, 171-180. Available online: http://link.springer.com/10.1007/s00784-014-1366-3 (accessed on 15 January 2021). [CrossRef]

6. Eichhorn, W.; Burkert, J.; Vorwig, O.; Blessmann, M.; Cachovan, G.; Zeuch, J.; Eichhorn, M.; Heiland, M. Bleeding Incidence after Oral Surgery with Continued Oral Anticoagulation. Clin. Oral Investig. 2012, 16, 1371-1376. Available online: http: / / link.springer.com/10.1007/s00784-011-0649-1 (accessed on 15 January 2021). [CrossRef]

7. Rocha, A.L.; Souza, A.F.; Martins, M.A.; Fraga, M.G.; Travassos, D.V.; Oliveira, A.C.; Ribeiro, D.D.; Silva, T.A. Oral surgery in patients under antithrombotic therapy: Perioperative bleeding as a significant risk factor for postoperative hemorrhage. Blood Coagul. Fibrinolysis 2018, 29, 97-103. [CrossRef]

8. Ng, D.L.C.; Gan, G.G.; Chai, C.S.; Chee, K.H.; Tan, K.L.; Tan, S.B.; Bee, P.C. Comparing quality of life and treatment satisfaction between patients on warfarin and direct oral anticoagulants: A cross-sectional study. Patient Prefer. Adherence 2019, 13, 1363-1373. [CrossRef]

9. Almiñana-Pastor, P.J.; Segarra-Vidal, M.; López-Roldán, A.; Alpiste-Illueca, F.M. A controlled clinical study of periodontal health in anticoagulated patients: Assessment of bleeding on probing. J. Clin. Exp. Dent. 2017, 9, e1431-e1438. [CrossRef] [PubMed]

10. Bartholomay, E.; Polli, I.; Borges, A.P.; Kalil, C.; Arroque, A.; Kohler, I.; Danzmann, L.C. Prevalence of Oral Anticoagulation in Atrial Fibrillation. Clinics 2014, 69, 615-620. Available online: http:/ / clinics.org.br/article.php?id=1372 (accessed on 15 January 2021). [CrossRef]

11. Martins, M.A.P.; Costa, J.M.; de Melo Mambrini, J.V.; Ribeiro, A.L.P.; Benjamin, E.J.; Brant, L.C.C.; Paasche-Orlow, M.K.; Magnani, J.W. Health literacy and warfarin therapy at two anticoagulation clinics in Brazil. Heart 2017, 103, 1089-1095. [CrossRef]

12. Purcell, C.A. Dental Management of the Anticoagulated Patient. N. Z. Dent. J. 1997, 93, 87-92. Available online: https: / / pubmed.ncbi.nlm.nih.gov/9323898/ (accessed on 15 January 2021).

13. Meurman, J.H.; Qvarnström, M.; Janket, S.J.; Nuutinen, P. Oral Health and Health Behavior in Patients Referred for Open-Heart Surgery. Oral Surg. Oral Med. Oral Pathol. Oral Radiol. Endodontol. 2003, 95, 300-307. Available online: https://pubmed.ncbi.nlm. nih.gov /12627100/ (accessed on 15 January 2021). [CrossRef]

14. Padrón, N.; Limeres, J.; Tomás, I.; Diz Dios, P. Oral Health and Health Behavior in Patients under Anticoagulation Therapy. Oral Surg. Oral Med. Oral Pathol. Oral Radiol. Endodontol. 2003, 96, 519-520. Available online: http://www.ncbi.nlm.nih.gov/pubmed/ 14658438 (accessed on 15 January 2021). [CrossRef]

15. Hanon, O.; Jeandel, C.; Jouanny, P.; Paccalin, M.; Puisieux, F.; Krolak-Salmon, P.; Berrut, G. Traitement Par Anticoagulants Chez Les Patients Atteints de Fibrillation Atriale: Un Consensus [Anticoagulant Treatment in Elderly Patients with Atrial Fibrillation: Position Paper]. Gériatrie Psychol. Neuropsychiatr. Vieil. 2019, 17, 341-355. Available online: https://pubmed.ncbi.nlm.nih.gov/31 848123 / (accessed on 15 January 2021).

16. Sharka, R.; Abed, H.; Hector, M. Oral health-related quality of life and satisfaction of edentulous patients using conventional complete dentures and implant-retained overdentures: An umbrella systematic review. Gerodontology 2019, 36, 195-204. [CrossRef] 
17. Perazzo, M.F.; Serra-Negra, J.M.; Firmino, R.T.; Pordeus, I.A.; Martins-JÚnior, P.A.; Paiva, S.M. Patient-centered assessments: How can they be used in dental clinical trials? Braz. Oral Res. 2020, 34, e075. [CrossRef] [PubMed]

18. Abdelrahim, R.; Delgado-Angulo, E.K.; Gallagher, J.E.; Bernabé, E. Ethnic Disparities in Oral Health Related Quality of Life among Adults in London, England. Community Dent Health 2017, 34, 122-127. Available online: https://pubmed.ncbi.nlm.nih. gov/28573845/ (accessed on 15 January 2021). [PubMed]

19. Wong, F.M.F.; Ng, Y.T.Y.; Keung Leung, W. Oral Health and Its Associated Factors among Older Institutionalized Residents-A Systematic Review. Int. J. Environ. Res. Public Health 2019, 16, 4132. Available online: https:/ / pubmed.ncbi.nlm.nih.gov/31717812/ (accessed on 15 January 2021). [CrossRef] [PubMed]

20. Schuster, A.; Pastorino, D.; Marcello-Machado, R.; Faot, F. Influence of Age and Time since Edentulism on Masticatory Function and Quality of Life in Implant-Retained Mandibular Overdenture Wearers: 1-year Results from a Paired Clinical Study. Int. J. Oral Maxillofac. Implant. 2019, 34, 1466-1474. Available online: https://pubmed.ncbi.nlm.nih.gov/31711087/ (accessed on 15 January 2021). [CrossRef]

21. Ortíz-Barrios, L.B.; Granados-García, V.; Cruz-Hervert, P.; Moreno-Tamayo, K.; Heredia-Ponce, E.; Sánchez-García, S. The impact of poor oral health on the oral health-related quality of life (OHRQoL) in older adults: The oral health status through a latent class analysis. BMC Oral Health 2019, 19, 141. [CrossRef] [PubMed]

22. Baiju, R.; Peter, E.; Varghese, N.; Varughese, J.; Sivaram, R.; Narayan, V. Development and initial validation of an oral healthrelated quality of life scale for older adolescents. Indian J. Dent. Res. 2019, 30, 826-833. [CrossRef]

23. van de Rijt, L.J.; Stoop, C.C.; Weijenberg, R.A.; de Vries, R.; Feast, A.R.; Sampson, E.L.; Lobbezoo, F. The Influence of Oral Health Factors on the Quality of Life in Older People: A Systematic Review. Gerontologist 2019, 60, e378-e394. Available online: https:/ / pubmed.ncbi.nlm.nih.gov/31729525/ (accessed on 15 January 2021). [CrossRef]

24. Trullas-Vila, J.C.; Freitas-Ramírez, A.; Soler-Simon, S.; Roncero-Vidal, J.M.; Gispert-Magarolas, R. Ten-Year Experience with Acenocoumarol Treatment in an Ambulatory Cohort of Spanish Patients. J. Thromb. Thrombolysis 2009, 28, 436-443. Available online: http:/ / www.ncbi.nlm.nih.gov/pubmed/19225864 (accessed on 15 January 2021). [CrossRef] [PubMed]

25. Molino-Pagan, D.; Andujar- Mateos, P.; Jornet, P. Analysis of General and Oral Quality of Life and Satisfaction with Treatment among Anticoagulated Patients. J. Dent. Oral Health 2015, 1, 1-4.

26. De Oliveira, B.H.; Nadanovsky, P. Psychometric properties of the Brazilian version of the Oral Health Impact Profile-Short form. Community Dent. Oral Epidemiol. 2005, 33, 307-314. [CrossRef]

27. Ulinski, K.G.B.; do Nascimento, M.A.; Lima, A.M.C.; Benetti, A.R.; Poli-Frederico, R.C.; Fernandes, K.B.P.; Fracasso, M.L.C.; Maciel, S.M. Factors Related to Oral Health-Related Quality of Life of Independent Brazilian Elderly. Int. J. Dent. 2013, 2013, 705047. [CrossRef]

28. Slade, G.D. Derivation and validation of a short-form oral health impact profile. Community Dent. Oral Epidemiol. 1997, 25, 284-290. [CrossRef]

29. Cyrino, R.M.; Miranda Cota, L.O.; Pereira Lages, E.J.; Bastos Lages, E.M.; Costa, F.O. Evaluation of Self-Reported Measures for Prediction of Periodontitis in a Sample of Brazilians. J. Periodontol. 2011, 82, 1693-1704. [CrossRef]

30. Laskin, D.M. Should prophylactic antibiotics be used for patients having removal of erupted teeth? Oral Maxillofac. Surg. Clin. 2011, 23, 537-539. Available online: http:/ / www.ncbi.nlm.nih.gov/pubmed/21982605 (accessed on 15 January 2021). [CrossRef]

31. Chu, V.H.; Sexton, D.J.; Cabell, C.H.; Barth, R.L.; Pappas, P.A.; Singh, R.K.; Fowler, V.G., Jr.; Ralph, C.G.; Aksoy, O.; Woods, C.W. Repeat Infective Endocarditis: Differentiating Relapse from Reinfection. Clin. Infect. Dis. 2005, 41, 406-409. Available online: http:/ / www.ncbi.nlm.nih.gov/pubmed/16007540 (accessed on 15 January 2021). [CrossRef] [PubMed]

32. Nishimura, R.A.; Carabello, B.A.; Faxon, D.P.; Freed, M.D.; Lytle, B.W.; O'Gara, P.T.; O’Rourke, R.A.; Shah, P.M. ACC/AHA 2008 Guideline Update on Valvular Heart Disease: Focused Update on Infective Endocarditis: A Report of the American College of Cardiology/American Heart Association Task Force on Practice Guidelines: Endorsed by the Society of Cardiovascular Anest. Circulation 2008, 118, 887-896. Available online: http:/ / www.ncbi.nlm.nih.gov/pubmed/18663090 (accessed on 15 January 2021). [CrossRef] [PubMed]

33. Petersen, P.E.; Baez, R.J.; World Health Organization. Oral health Surveys: Basic Methods, 5th ed.; World Health Organization: Geneva, Switzerland, 2013; Available online: http:/ /apps.who.int/iris/handle/10665/97035 (accessed on 15 January 2021).

34. Hosmer, D.W.; Lemeshow, S.; Sturdivant, R.X. Applied Logistic Regression, 3rd ed.; Wiley: New York, NY, USA, 2013 ; p. 500.

35. Long, J.S. Regression Models for Categorical and Limited Dependent Variables, 1st ed.; Sage Publications: Thousand Oaks, CA, USA, $1997 ;$ p. 297.

36. Spanemberg, J.C.; Cardoso, J.A.; Slob, E.M.G.B.; López-López, J. Quality of Life Related to Oral Health and Its Impact in Adults. J. Stomatol. Oral Maxillofac. Surg. 2019, 120, 234-239. Available online: https://pubmed.ncbi.nlm.nih.gov/30763780/ (accessed on 15 January 2021). [CrossRef] [PubMed]

37. Yang, S.E.; Park, Y.G.; Han, K.; Min, J.A.; Kim, S.Y. Dental Pain Related to Quality of Life and Mental Health in South Korean Adults. Psychol. Health Med. 2016, 21, 981-992. Available online: https://pubmed.ncbi.nlm.nih.gov/26456324/ (accessed on 15 January 2021). [CrossRef]

38. Dye, B.A.; Tan, S.; Smith, V.; Barker, L.K.; Thornton-Evans, G.; Eke, P.I.; Beltraán-Aguilar, E.D. Trends in oral health status: United States, 1988-1994 and 1999-2004. Vital Health Stat. 2007, 11, 1-92.

39. Elani, H.W.; Harper, S.; Allison, P.J.; Bedos, C.; Kaufman, J.S. Socio-Economic Inequalities and Oral Health in Canada and the United States. J. Dent. Res. 2012, 91, 865-870. Available online: https://pubmed.ncbi.nlm.nih.gov/22837551/ (accessed on 15 January 2021). [CrossRef] 
40. Hjern, A.; Grindefjord, M. Dental health and access to dental care for ethnic minorities in Sweden. Ethn. Health 2000, 5, 23-32. Available online: https:/ / pubmed.ncbi.nlm.nih.gov/10858936/ (accessed on 15 January 2021). [CrossRef]

41. Sánchez-García, S.; Juárez-Cedillo, T.; Reyes-Morales, H.; De La Fuente-Hernández, J.; Solórzano-Santos, F.; García-Peña, C. State of Dentition and Its Impact on the Capacity of Elders to Perform Daily Activities. Salud Publica Mex. 2007, 49, 173-181. Available online: https:/ / pubmed.ncbi.nlm.nih.gov/17589771/ (accessed on 15 January 2021). [CrossRef]

42. Cho, M.J.; Kim, E.K. Subjective Chewing Ability and Health-Related Quality of Life among the Elderly. Gerodontology 2019, 36, 99-106. Available online: https:/ / pubmed.ncbi.nlm.nih.gov/30565311/ (accessed on 15 January 2021). [CrossRef]

43. Alkhatib, M.N.; Holt, R.; Bedi, R. Age and Perception of Dental Appearance and Tooth Colour. Gerodontology 2005, 22, 32-36. Available online: https:/ / pubmed.ncbi.nlm.nih.gov/15747896/ (accessed on 15 January 2021). [CrossRef]

44. Karasneh, J.; Al-Omiri, M.K.; Al-Hamad, K.Q.; Al Quran, F.A.M.A. Relationship between Patients' Oral Health-Related Quality of Life, Satisfaction with Dentition, and Personality Profiles. J. Contemp. Dent. Pract. 2009, 10, 49-56. Available online: https: / / pubmed.ncbi.nlm.nih.gov/20020081/ (accessed on 15 January 2021).

45. Sonnenschein, S.K.; Betzler, C.; Kohnen, R.; Krisam, J.; Kim, T.S. Oral health-related quality of life in patients under supportive periodontal therapy. Acta Odontol. Scand. 2018, 76, 572-579. [CrossRef] [PubMed]

46. Llanos, A.H.; Benítez Silva, C.G.; Ichimura, K.T.; Rebeis, E.S.; Giudicissi, M.; Romano, M.M.; Saraiva, L. Impact of aggressive periodontitis and chronic periodontitis on oral health-related quality of life. Braz. Oral Res. 2018, 32, 1-7. [CrossRef]

47. Durham, J.; Fraser, H.M.; McCracken, G.I.; Stone, K.M.; John, M.T.; Preshaw, P.M. Impact of periodontitis on oral health-related quality of life. J. Dent. 2013, 41, 370-376. [CrossRef] [PubMed]

48. Masood, M.; Younis, L.T.; Masood, Y.; Bakri, N.N.; Christian, B. Relationship of periodontal disease and domains of oral health-related quality of life. J. Clin. Periodontol. 2019, 46, 170-180. [CrossRef]

49. Gerritsen, A.E.; Allen, P.F.; Witter, D.J.; Bronkhorst, E.M.; Creugers, N.H.J. Tooth Loss and Oral Health-Related Quality of Life: A Systematic Review and Meta-Analysis. Health Qual. Life Outcomes 2010, 8, 126. Available online: http:/ / www.hqlo.com/content/8/1/126 (accessed on 15 January 2021). [CrossRef]

50. Oliveira, D.C.; Ferreira, F.M.; Morosini, I.D.A.; Torres-Pereira, C.C.; Paiva, S.M.; Fraiz, F.C. Impact of oral health status on the oral health-related quality of life of Brazilian male incarcerated adolescents. Oral Health Prev. Dent. 2015, 13, 417-425.

51. Kassebaum, N.J.; Bernabé, E.; Dahiya, M.; Bhandari, B.; Murray, C.J.L.; Marcenes, W. Global Burden of Untreated Caries: A Systematic Review and Metaregression. J. Dent. Res. 2015, 94, 650-658. Available online: https://pubmed.ncbi.nlm.nih.gov/25740856/ (accessed on 15 January 2021). [CrossRef]

52. Baelum, V. Dentistry and population approaches for preventing dental diseases. J. Dent. 2011, 39 (Suppl. S2), S9-S19. [CrossRef]

53. Haag, D.G.; Peres, K.G.; Balasubramanian, M.; Brennan, D.S. Oral Conditions and Health-Related Quality of Life: A Systematic Review. J. Dent. Res. 2017, 96, 864-874. Available online: https:/ / pubmed.ncbi.nlm.nih.gov/28581891/ (accessed on 15 January 2021). [CrossRef]

54. Ugochukwu, C.; Bagot, K.S.; Delaloye, S.; Pi, S.; Vien, L.; Garvey, T.; Bolotaulo, N.I.; Kumar, N.; IsHak, W.W. The Importance of Quality of Life in Patients with Alcohol Abuse and Dependence. Harv. Rev. Psychiatry 2013, 21, 1-17. Available online: https:/ / pubmed.ncbi.nlm.nih.gov/23656759/ (accessed on 15 January 2021). [CrossRef] [PubMed]

55. Rodríguez-Almagro, J.; García-Manzanares, Á.; Lucendo, A.J.; Hernández-Martínez, A. Health-Related Quality of Life in Diabetes Mellitus and Its Social, Demographic and Clinical Determinants: A Nationwide Cross-Sectional Survey. J. Clin. Nurs. 2018, 27, 4212-4223. Available online: https:/ / pubmed.ncbi.nlm.nih.gov/29987853/ (accessed on 15 January 2021). [CrossRef] [PubMed]

56. Goldenberg, M.; Danovitch, I.; IsHak, W.W. Quality of Life and Smoking. Am. J. Addict. 2014, 23, 540-562. Available online: https: / / pubmed.ncbi.nlm.nih.gov/25255868/ (accessed on 15 January 2021). [CrossRef] [PubMed]

57. Faot, F.; Martins, A.P.P.; Marcello-Machado, R.M.; Schuster, A.J.; Bielemann, A.M.; Nascimento, G.G.; Melo, A.C.M.; de Rezende Pinto, L. Influence of Facial Patterns on the Masticatory Function and Quality of Life of Completely Edentulous Patients during the Transition to Implant-Retained Mandibular Overdentures. J. Prosthet. Dent. 2019, 122, 450-458. Available online: https:/ / pubmed.ncbi.nlm.nih.gov/30948299/ (accessed on 15 January 2021). [CrossRef] [PubMed]

58. Figueredo, O.M.C.; Câmara-Souza, M.B.; Carletti, T.M.; Rodrigues Garcia, R.C.M. Chewing Ability and Oral Health-Related Quality of Life in Frail Elders after New Complete Dentures Insertion: A Paired Controlled Clinical Trial. Spec. Care Dent. 2020, 40, 168-174. Available online: https://pubmed.ncbi.nlm.nih.gov/31943301/ (accessed on 15 January 2021). [CrossRef] [PubMed]

59. Myint Oo, K.Z.; Fueki, K.; Yoshida-Kohno, E.; Hayashi, Y.; Inamochi, Y.; Wakabayashi, N. Minimal Clinically Important Differences of Oral Health-Related Quality of Life after Removable Partial Denture Treatments. J. Dent. 2020, 92, 103246. Available online: https:/ / pubmed.ncbi.nlm.nih.gov/31738967/ (accessed on 15 January 2021). [CrossRef]

60. Bagewitz, I.; Söderfeldt, B.; Palmqvist, S.; Nilner, K. Oral prostheses and oral health-related quality of life: A survey study of an adult Swedish population. Int. J. Prosthodont. 2007, 20, 134-142.

61. Ali, Z.; Baker, S.R.; Shahrbaf, S.; Martin, N.; Vettore, M.V. Oral health-related quality of life after prosthodontic treatment for patients with partial edentulism: A systematic review and meta-analysis. J. Prosthet. Dent. 2019, 121, 59-68.e3. [CrossRef] [PubMed]

62. Olsen, J.; Christensen, K.; Murray, J.; Ekbom, A. The Cross-Sectional Study. In An Introduction to Epidemiology for Health Professionals; Springer: New York, NY, USA, 2010; Available online: https://link.springer.com/chapter/10.1007/978-1-4419-1497-2_11 (accessed on 15 January 2021).

63. Arnett, D.K.; Claas, S.A. Introduction to Epidemiology. In Clinical and Translational Science: Principles of Human Research, 2nd ed.; Robertson, D., Gordon, H.W., Eds.; Academic Press: Cambridge, MA, USA; Elsevier Inc.: London, UK, 2017 ; pp. 53-69. 